\title{
A restorer gene in gynodioecious Plantago coronopus subject to selection in the gametophytic and seedling stage
}

\author{
J. M. M. VAN DAMME \\ Department of Plant Ecology, Institute for Ecological Research, Boterhoeksestraat 22, P.O. Box 40, 6666 ZG Heteren, \\ The Netherlands
}

\begin{abstract}
The genetic basis of male sterility in the gynodioecious species Plantago coronopus was studied. As the aim was to find strains with a single, varying nuclear locus for male sterility, cytoplasmic variation was avoided by starting with one open pollinated female. The progeny appeared to vary for a single locus with the homozygous recessive being male sterile. The locus was designated msl. Expected segregation ratios were disturbed by two different factors, both leading to a shortage of male steriles. An accidental drought in Petri dishes caused a relatively higher mortality of seedlings with a male sterility genotype in most cases. When this effect was avoided a systematic shortage of male steriles remained in many crosses. An experiment with varying levels of pollen competition justified the interpretation that selection at the gametophytic stage was involved. Pollen carrying the sterility allele was estimated to have a fertilization success relative to pollen with the restorer allele of 0.56 . Finally the role of the $m s 1$ locus in the genetics of male sterility in natural populations was assessed by crossing heterozygously and homozygously restored plants with male steriles collected from the wild. It appeared that the inheritance of male sterility is more complicated than the $m s l$ locus alone, which was expected. If the selection effects on the msl locus observed in this study occur in nature, this would have interesting consequences for the evolutionary dynamics of gynodioecy.
\end{abstract}

Keywords: gynodioecy, Plantago coronopus, pollen competition, restorer gene.

\section{Introduction}

Gynodioecy is a sexual system where a population consists of a mixture of male sterile plants (females) and hermaphrodites that interbreed. The genetics of male sterility have only been solved in a limited number of cases. Detailed genetic studies of natural populations show that male sterility is determined by a combination of nuclear and cytoplasmic genes (KheyrPour, 1981; Van Damme, 1983), whereas in other studies the involvement of the cytoplasm was implied by a lack of explanatory power of models with nuclear genes only (Kesseli \& Jain, 1984; Sun, 1987). These results are in agreement with information from many agricultural species, where nuclear-cytoplasmic inheritance forms the basis for the production of hybrids (Kaul, 1988).

The evolutionary dynamics of gynodioecy is best understood as a conflict of interests between nuclear and cytoplasmic genes (Gouyon \& Couvet, 1985). Mutations in the cytoplasmic DNA causing male sterility (CMS) of the plant, and at the same time a slight increase in female fertility, can easily spread in a population. However, at high male sterile frequency nuclear alleles, which restore male fertility of plants carrying the CMS cytoplasm, will have a fitness advantage over competing alleles, because at this stage male fertile plants will acquire most of their fitness through pollen. These restorer alleles will thus spread and the male sterile frequency drops. Gynodioecious populations are typically thought to consist of two or more cytoplasmic types, while for each cytoplasm one or more restorer loci exist.

The conflict between nuclear and cytoplasmic genes generates varying gene frequencies over time, expressed at the phenotypic levels as pulses of high male sterile frequency, alternating with periods of low frequencies, or even absence, of male steriles (Frank, 1989; Gouyon et al., 1990).

Theoretical studies have shown that two basic forces are important for the dynamics of the gynodioecious system (Charlesworth, 1981; Frank, 1989; Gouyon et 
al., 1990). Firstly, male sterile plants should have at least some fitness advantage over hermaphrodites in seed production during their lifetime or in offspring quality. Secondly, restorer alleles should cause, as a pleiotropic effect, a disadvantage to plants that carry a cytoplasmic type of which the restorer allele does not restore male fertility. The former effect has often been found: in many species male steriles have a 10-100 per cent advantage over hermaphrodites in (components of) seed production (reviewed in Gouyon \& Couvet, 1987). However, evidence for the existence of associated negative fitness effects of restorer alleles is lacking. In order to detect such an effect it is necessary to compare genotypes with and without the restorer allele. Since this comparison should be made in a cytoplasmic background, where the restorer allele is inactive, these genotypes will have the same (hemaphrodite) sex phenotype. It is clear that genetic knowledge should be available to obtain direct evidence for the existence of such effects. Genetic studies of male sterility in gynodioecious species are, in this respect, often unsatisfactory because of a lack of precision. Furthermore, the situation is complex: evidence has been found for the existence of several restorer loci for each cytoplasm (Van Damme, 1983; Connor \& Charlesworth, 1989).

Male sterility in Plantago coronopus is known to have nuclear-cytoplasmic inheritance of male sterility (H. P. Koelewijn \& J. M. M. Van Damme, in preparation). The present report concerns a genetic study of a restorer locus in $P$. coronopus, and is part of an attempt to isolate lines in which a single restorer locus varies. A study of the fitness effects of the restorer allele can be undertaken using lines such as these by crossing it into suitable cytoplasmic and nuclear backgrounds. The line reported here gave problems with the interpretation of the crossing results which appeared to be caused by selective differences beween the restorer and the sterility allele in the gametophytic and the seedling stage. Such differences have potentially interesting effects on the dynamics of the gynodioecious system.

\section{Materials and methods}

In the Netherlands, $P$. coronopus is an annual or shortlived perennial, mainly growing on sandy soils along the coast. Open pollinated spikes were collected at the 'Strandvlakte', a beach plain on the east of the island of Schiermonnikoog. Three male sterile plants and three hermaphrodites grown from seeds of a single MS spike were used as starting material for the crosses, so that variation in sex type in the progenies could not be due to cytoplasmic variation.
Self fertilization of hermaphrodites and crosses between male steriles and hermaphrodites were achieved by enclosing spikes with paper bags and tapping these regularly during male flowering. This procedure resulted in thousands of pollen grains per style, more than sufficient for the five ovules per flower in this species (Dowling, 1933). Although the flowers of $P$. coronopus are protogynous, there is a considerable overlap between male and female flowering of the same spike. Therefore, for crosses beween hermaphrodites, plants serving as ovule parents were pretreated by enclosing them in plastic bags to retain the moisture level around the plant at 100 per cent. Anthers do not open spontaneously under these conditions and exerted anthers were removed when the female phase of a sufficient number of spikes was fully developed.

In the course of this study some crosses were made to test for the possibility of selection during pollen competition. Use was made of the characteristic of Plantago species that the feathery style, which is receptive over almost its entire length, continues to grow for about 1 week provided that there is no fertilization of the ovules. A high competition level was obtained by collecting pollen on filter paper and rolling the female flowering spike to and fro in the pollen at a late flowering stage when the styles were about $15 \mathrm{~mm}$ long. This mode of pollination results in very high pollen loads on the styles, comparable to the bagging method. A low competition level was achieved by brushing a small amount of pollen (about 30-40 grains) on each flower separately, when the styles were only a few millimetres long.

Seeds were germinated in Petri dishes with moist filter paper. Seeds that did not germinate spontaneously within 1 week were cut at the side of the radicle, which appeared to stimulate germination. Seedlings were transferred to 0.7 pots filled with potting compost. All plants were grown in the greenhouse with $16 \mathrm{~h}$ light per day and a day-night temperature regime of $21-17^{\circ} \mathrm{C}$. Flowering started within $6-8$ weeks after sowing. Total survival from seed to flowering, inclusive of germination, was at least 90 per cent (except for one series, see Results).

Sex type was scored when at least five spikes were flowering per plant. Sex expression appeared to depend partly on the environment. Two sex types could be distinguished.

1 Male sterile plants (MS) with small brown anthers without pollen and short filaments. The MS type morphologically closely resembles the MS1 male sterility type of $P$. lanceolata (Van Damme \& van Delden, 1982), and is stable in expression.

2 Hermaphrodites $(\mathrm{H})$, with four fertile anthers per 
flower. Many of the $\mathrm{H}$ plants could temporarily show partial male sterility depending on circumstances (probably temperature). Partial male sterility was generally expressed as a mixture of hermaphrodite and male sterile flowers on the spikes, together with flowers with intermediate anther types (cf. IN1 in P. lanceolata, ibid). The ability to show partial male sterility was not used for distinctions within the hermaphrodite class. In some crosses a maximum of 10 per cent of the plants persisted in being MS except for some flowers that had intermediate or fertile anthers. These plants were classified as MS plants.

All ratios are presented as $\mathrm{MS}: \mathrm{H}$ ratios, and have been analysed with the $G$-test (Sokal \& Rohlf, 1981).

\section{Results}

\section{A single male sterility locus}

The progeny of the open pollinated MS plant that was used as the basis for this study segregated for male sterility. Three $\mathrm{H}$ plants from this progeny were selffertilized, and each was crossed with a MS plant from the same progeny. All three $H$ plants gave $1: 3$ ratios upon selfing, and all three MS $\times \mathbf{H}$ crosses 1:1 ratios (Table 1). These results suggest that male sterility in this line is inherited by a single locus with two alleles, say $R$ and $r$, with $r r$ plants with the male sterile phenotype. The sterility allele $r$ is thus recessive, or, alternatively the restorer allele $R$ dominant. All three $\mathrm{H}$ plants used as parents should then be heterozygous.

To test this genetic model, a number of $\mathrm{H}$ plants from each of the three selfed progenies were selffertilized. Under the one locus model one-third of these selfings are expected to yield only $\mathrm{H}$ plants while two-thirds should (i) segregate MS, and (ii) yield a MS: $\mathrm{H}$ ratio of $1: 3$. The progenies were grown in two series represented in Table 2 by progeny 1 and 2 , respectively. A drought accidentally occurred during the germination phase in many of the dishes of the first series. About half the seedlings died, but not all the Petri dishes were equally affected. One selfing was completely lost. Seedlings were grown from all dishes that had any living seedlings left. A second series of progenies was germinated and grown for part of the selfings as a control, with an overall survival inclusive of germination of 93 per cent. The results of the selfings that did not segregate MS plants in both series were combined (Table 2). Summed over the three families, 24 plants segregated MS, and 14 did not. This result is compatible with a $2: 1$ ratio $(G=0.21$, d.f. $=1$, ns), while there was no heterogeneity among families $(G=3.89$, d.f. $=2$, ns $)$.

The MS: $\mathrm{H}$ ratios in the segregating progenies, however, did not in general fit the expected 1:3 ratio (Table 3). Only the progenies of the second series in family 43 segregated as expected. Heterogeneity among progenies within families and series was relatively small. There was, however, a considerable difference in the fraction of MS between the two series, also when analysis is restricted to the progenies of those plants that were used as parents in both series (Table 2, $G=16.25$, d.f. $=1, P<0.001)$. Furthermore, the difference varied among families (Table 3 ): there was no difference for family 36 , while the shift in the fraction MS from the first to the second series was of comparable size in the two other families. The difference between the series is also clear at the level of individual

Table 1 The first generation of crosses and selfings of descendants of a single male sterile $P$. coronopus plant. The $G$-values are given for expected MS: $\mathrm{H}$ ratios $($ d.f. $=1$ ) and heterogeneity (d.f. $=2)$

\begin{tabular}{|c|c|c|c|c|c|c|c|}
\hline \multirow[b]{2}{*}{ Family } & \multirow[b]{2}{*}{ Cross } & \multicolumn{2}{|c|}{ Offspring } & \multirow[b]{2}{*}{ Fraction MS } & \multirow{2}{*}{\multicolumn{2}{|c|}{$G$ (ratio) }} & \multirow[b]{2}{*}{$G$ (het) } \\
\hline & & MS & $\mathrm{H}$ & & & & \\
\hline & $\mathrm{MS}-7 \times \mathrm{H}-2$ & 59 & 51 & 0.54 & 0.582 & & \\
\hline & MS $-9 \times$ H-3 & 65 & 75 & 0.46 & 0.715 & & \\
\hline & MS $-5 \times$ H- 1 & 25 & 22 & 0.53 & 0.192 & $1: 1$ & \\
\hline & Total & 149 & 148 & 0.50 & 0.003 & & 1.485 \\
\hline \multirow{5}{*}{$\begin{array}{l}36 \\
40 \\
43\end{array}$} & Selfing & & & & & & \\
\hline & $\mathrm{H}-2$ & 27 & 69 & 0.28 & 0.487 & \multirow{4}{*}{$1: 3$} & \\
\hline & $\mathrm{H}-3$ & 15 & 60 & 0.20 & 1.050 & & \\
\hline & $\mathrm{H}-1$ & 20 & 45 & 0.31 & 1.102 & & \\
\hline & Total & 62 & 174 & 0.26 & 0.201 & & 2.438 \\
\hline
\end{tabular}


Table 2. Second generation of selfings of hermaphrodites from three families in Table 1. Deviations from expected 1:3 MS: $\mathrm{H}$ ratios in the segregating selfings are tested with the $G$-test. Significance levels in this and the following tables are given as ${ }^{*} P<0.05$; ${ }^{* *} P<0.01 ;{ }^{* * *} P<0.001$. The significance indications, including ns ( = non significant), between brackets refer to a correction for gametophytic selection. For further explanation see text

\begin{tabular}{|c|c|c|c|c|c|c|c|}
\hline \multirow[b]{3}{*}{ Parent } & \multicolumn{4}{|c|}{ Segregating } & \multicolumn{3}{|c|}{ Non-segregating } \\
\hline & \multicolumn{2}{|c|}{ Progeny 1} & \multicolumn{2}{|c|}{ Progeny 2} & \multirow[b]{2}{*}{ Parent } & \multicolumn{2}{|c|}{ Progeny } \\
\hline & MS & $\mathrm{H}$ & MS & $\mathrm{H}$ & & MS & $\mathrm{H}$ \\
\hline \multicolumn{8}{|c|}{ Family 36 (H-2 selfing) } \\
\hline 1 & 4 & 20 & & & 5 & 0 & 68 \\
\hline 2 & 6 & 16 & & & 6 & 0 & 55 \\
\hline 3 & 4 & 19 & & & 10 & 0 & 110 \\
\hline 4 & 1 & $23^{*}$ & 9 & 46 & 15 & 0 & 73 \\
\hline 7 & 2 & 12 & 11 & 40 & & & \\
\hline 8 & 5 & 19 & 4 & 29 & & & \\
\hline 13 & 5 & 19 & 5 & 28 & & & \\
\hline 16 & 6 & 18 & & & & & \\
\hline Total & 33 & $146^{*}(\mathrm{~ns})$ & 29 & $143^{*}(\mathrm{~ns})$ & & 0 & 306 \\
\hline \multicolumn{8}{|c|}{ Family 40 (H-3 selfing) } \\
\hline 4 & 0 & $24 * *$ & 8 & 42 & 3 & 0 & 72 \\
\hline 12 & 1 & $23^{*}$ & 5 & 23 & 11 & 0 & 74 \\
\hline 19 & 2 & $26^{*}$ & 23 & 84 & 17 & 0 & 5 \\
\hline 20 & 4 & 18 & 8 & 21 & 18 & 0 & 37 \\
\hline 30 & 1 & $23^{*}$ & 12 & $94^{* * *}(\mathrm{~ns})$ & 27 & 0 & 64 \\
\hline & & & & & 28 & 0 & 74 \\
\hline & & & & & 29 & 0 & 74 \\
\hline Total & 8 & $114^{* * *}(* *)$ & 56 & $264^{* * *}$ (ns) & & 0 & 400 \\
\hline \multicolumn{8}{|c|}{ Family 43 ( $\mathrm{H}-1$ selfing) } \\
\hline 5 & 4 & 20 & & & 6 & 0 & 24 \\
\hline 7 & 1 & 5 & & & 9 & 0 & 92 \\
\hline 8 & 3 & 21 & 4 & 5 & 18 & 0 & 74 \\
\hline 10 & 7 & 17 & 9 & 15 & & & \\
\hline 11 & 2 & 24 & & & & & \\
\hline 12 & 4 & 20 & & & & & \\
\hline 13 & 7 & 17 & 1 & 8 & & & \\
\hline 14 & 5 & $43^{*}$ & & & & & \\
\hline 17 & 0 & $24^{* *}$ & 10 & 34 & & & \\
\hline 19 & 1 & $23^{*}$ & 43 & 108 & & & \\
\hline 20 & 2 & 22 & 28 & 80 & & & \\
\hline Total & 36 & $236^{* * *}(\mathrm{~ns})$ & 95 & $250 \mathrm{~ns}(* * *)$ & & 0 & 190 \\
\hline
\end{tabular}

progenies (Table 2). Two selfings were misclassified after the first series as non-segregating, but they appeared to be neatly segregating in the second series (selfing 40-4 and 43-17, Table 2). One of the causes of the deviations from expectation is likely to be the drought, which occurred just after germination in series 1 , since series 1 and 2 differed in this respect. It is feasible that MS seedlings survived less well during the drought than $\mathrm{H}$ seedlings. Comparison of the mean family results (Table 3 ) shows that, although this effect is sufficient to explain the deviation from 1:3 in family 43 , it only partly explains why family 40 does not fit that ratio (fraction of MS in second series only 0.18 ), and seems to play no role in family 36 (no difference between series).

Further predictions from the one locus model are that $\mathrm{H}$ plants that segregate after selfing, give a $1: 1$ ratio when crossed to MS plants and a 1:3 ratio when 
Table 3 Summary and $G$-analysis of the segregating progenies in Table 2. The $G$-values for heterogeneity are given for among progenies within families and for between families within series

\begin{tabular}{|c|c|c|c|c|c|c|c|c|}
\hline \multirow[b]{2}{*}{ Family } & \multicolumn{4}{|c|}{ Progeny series 1} & \multicolumn{4}{|c|}{ Progeny series 2} \\
\hline & Fraction MS & $G(1: 3)$ & d.f. (het) & $G$ (het) & Fraction MS & $G(1: 3)$ & d.f. (het) & $G($ het $)$ \\
\hline 36 & 0.18 & $4.397^{*}$ & 7 & 6.523 & 0.17 & $6.621^{*}$ & 3 & 1.410 \\
\hline 40 & 0.07 & $28.715^{* * * *}$ & 4 & 7.157 & 0.18 & $10.376^{* * *}$ & 4 & 6.132 \\
\hline 43 & 0.13 & $22.985^{* * *}$ & 10 & $19.658^{*}$ & 0.28 & 1.158 & 5 & 4.487 \\
\hline Total & 0.13 & $46.624^{* * *}$ & 2 & $9.473^{* *}$ & 0.22 & $5.636^{*}$ & 2 & $12.519^{* *}$ \\
\hline
\end{tabular}

Table 4 Second generation of crosses of male steriles (MS) with hermaphrodites that segregated after selfing (Hs) and with hermaphrodites that failed to segregate after selfing (Hns). The significance indications between brackets refer to a correction for gametophytic selection. For further explanation see text

\begin{tabular}{|c|c|c|c|c|c|c|c|c|}
\hline \multirow[b]{2}{*}{ Family } & \multirow[b]{2}{*}{ Cross } & \multicolumn{2}{|c|}{ Offspring } & \multirow[b]{2}{*}{ Fraction MS } & \multirow[b]{2}{*}{$G($ ratio $)$} & \multirow[b]{2}{*}{ Cross } & \multicolumn{2}{|c|}{ Offspring } \\
\hline & & MS & $\mathrm{H}$ & & & & MS & $\mathrm{H}$ \\
\hline \multirow{12}{*}{422} & $\mathrm{MS} \times \mathrm{Hs}$ & & & & $1: 1$ & $\mathrm{MS} \times \mathrm{Hns}$ & & \\
\hline & $43-2 \times 40-20$ & 24 & 40 & 0.38 & $4.043^{*}(\mathrm{~ns})$ & $43-24 \times 40-11$ & 0 & 36 \\
\hline & $40-7 \times 43-5$ & 30 & 68 & 0.31 & $15.128^{* * * *}(\mathrm{~ns})$ & $43-2 \times 40-28$ & 0 & 45 \\
\hline & $40-6 \times 43-12$ & 25 & 38 & 0.40 & 2.702 & $40-15 \times 43-18$ & 0 & 102 \\
\hline & & & & & & $40-8 \times 43-9$ & 0 & 58 \\
\hline & Total & 79 & $146 \dagger$ & 0.35 & $20.257^{* * *}(\mathrm{~ns})$ & Total & 0 & 241 \\
\hline & $\mathrm{Hs} \times \mathrm{Hs}$ & & & & $1: 3$ & Hns $\times$ Hns & & \\
\hline & $40-19 \times 43-19$ & 11 & 39 & 0.22 & 0.247 & $43-9 \times 40-28$ & 0 & 49 \\
\hline & $43-20 \times 40-30$ & 5 & 45 & 0.10 & $7.246^{* *}(\mathrm{~ns})$ & $40-3 \times 43-18$ & 0 & 30 \\
\hline & $40-30 \times 43-19$ & 4 & 46 & 0.08 & $9.680^{* *}(*)$ & $40-11 \times 43-18$ & 0 & 32 \\
\hline & $43-19 \times 40-30$ & 16 & 69 & 0.19 & 1.840 & & & \\
\hline & Total & 36 & $199 \ddagger$ & 0.15 & $13.054^{* * *}(\mathrm{~ns})$ & Total & 0 & 111 \\
\hline
\end{tabular}

$\dagger G$ for heterogeneity $=1.616$, d.f. $=2$, n.s.

$\ddagger G$ for heterogeneity $=5.959$, d.f. $=3$, n.s.

crossed to each other. Non-segregating $\mathrm{H}$ plants, however, should give a $0: 1$ ratio in both types of crosses. A number of crosses have been made for each case (Table 4). Qualitatively the results were as expected, but there was again an overall shortage of MS in segregating progenies. There was no significant heterogeneity among progenies in this respect (Table 4).

To sum up, the one locus model qualitatively fits the results of the crossing programme, although in most crosses there is a shortage of MS plants. Where seedling mortality occurred, it only explained part of the shortage of MS (Table 2). Clearly other factors must be involved.

\section{Gametophytic selection}

The deviations from expected ratios observed in the crossing programme, discussed above, appear to show a consistent pattern. The MS fractions in the progenies where a 1:3 ratio was expected but not found, are similar: 0.17 and 0.18 in families 36 and 40 , respectively (Table 3 second series), and 0.15 in the crosses between segregating $\mathrm{H}$ plants (Table 4 ). This reduction in frequency relative to the expected 0.25 is comparable to the reduction observed in crosses between MS and $\mathrm{H}$ (Table 4 ) where a 1:1 was expected, but the fraction of MS was 0.35 instead of 0.50 . Such deficiencies in MS frequency would be expected if selec- 
tion acts against the sterility allele during pollen competition: under these circumstances the relative reduction in the fraction of MS is then the same for an expected $1: 3$ and $1: 1$ ratio.

To test this hypothesis, four crosses between MS plants and presumed heterozygote $\mathrm{H}$ plants were performed under conditions of a low and a high level of pollen competition, the latter being similar to the level in other crosses of this study. In all crosses a 1:1 ratio is expected provided that there is no selection at either competition level. Under the high level of pollen competition the average fraction of MS among offspring was 0.38 , which is significantly different from that expected (Table 5). This is consistent with the deviation observed in the previous generation (Table 4). In contrast, the results obtained at the low competition level fit the expected $1: 1$ ratio, indicating that no gametophytic selection had occurred (Table 5). The $G$ value of heterogeneity between the treatment totals was 3.78 (d.f. $=1, P=0.052$ ), at the limit of significance.

From the deviations a coefficient of selection $s$, defined as the fertilization success of the sterility allele $r$ relative to that of $R$, under strongly competitive circumstances, can be estimated. The expected ratios now change from $1: 3$ to $1:[(2+s) / s]$, and from $1: 1$ to $1:(1 / s)$. They become identical to the original ratios for $s=1$. Using the $G$-test in an iterative procedure, the value of $s$ was assessed for which the $G$-ratio value, in selfings and crosses showing a shortage of MS, was minimized. A minimum $G$-value corresponds to an optimum of $s$. With the same procedure a 95 per cent confidence interval was estimated. The progenies of the second series of the families 36 and 40 in Table 2, and of the crosses between segregating $\mathrm{H}$ plants in Table 4 , i.e. three groups with 4,5 , and 4 progenies, respectively, were tested against the ratio $1:[(2+s) / s]$.
Furthermore, the ratio $1:(1 / s)$ was used for the progenies of the segregating crosses between MS and $\mathrm{H}$ in Table 4 and of the high competition series in Table 5 , i.e. groups with 3 and 4 progenies, respectively. Testing all groups of progenies simultaneously yielded an optimum $s$ of 0.556 (confidence interval $0.47-0.66$ ). The expected MS fractions in this case are 0.18 and 0.36 instead of 0.25 and 0.50 , respectively. The fit appears to be satisfactory for all five group totals, and for most individual progenies except for two: the cross 40-30 $\times 43-19$ (Table 4) still has a significant shortage of MS, and the high competition score of 422$14 \times 422-7$, which fitted a $1: 1$, has now a surplus of MS.

In conclusion, if selective death of MS seedlings and the lowered fertility success of $r$ pollen, when in competition with $R$ pollen, are taken into account, then the results of crosses reported here can be explained in terms of a nuclear one locus model. This locus will be designated as $m s l$.

\section{The role of the ms1 locus in the genetics of male sterility}

To test whether variation at the $m s 1$ locus can explain the genetic variation for male sterility in natural populations, four new MS plants were collected from the same population (Strandvlakte) where $m s 1$ was found, and another five from a population at several kilometres distance, but on the same island (Waddendijk). Morphologically the nine MS plants could not be distinguished from MS plants of the $m s 1$ line. Each plant was crossed to an $\mathrm{H}$ plant heterozygous $R r$ and to an $\mathrm{H}$ plant homozygous $R R$. Two of the four plants from the Strandvlakte behaved as if the $m s 1$ locus was involved in their sex determination, but the other two

Table 5 Third generation of crosses between male steriles (MS) and hermaphrodites segregating in selfings (Hs). Two levels of pollen competition were used. The significance indications between brackets refer to a correction for gametophytic selection. For further explanation see text

\begin{tabular}{|c|c|c|c|c|c|c|c|c|}
\hline \multirow[b]{2}{*}{ Cross } & \multicolumn{4}{|c|}{ Low competition level } & \multicolumn{4}{|c|}{ High competition level } \\
\hline & MS & $\mathrm{H}$ & Fraction MS & $G(1: 1)$ & MS & $\mathrm{H}$ & Fraction MS & $G(1: 1)$ \\
\hline \multicolumn{9}{|c|}{ Family 422 (MS-40-7 $\times$ Hs-43-5) } \\
\hline $11 \times 5$ & 35 & 43 & 0.45 & 0.822 & 36 & 69 & 0.34 & $10.549^{* *}(\mathrm{~ns})$ \\
\hline $12 \times 9$ & 52 & 65 & 0.44 & 1.447 & 35 & 59 & 0.37 & $6.196^{*}(\mathrm{~ns})$ \\
\hline $14 \times 7$ & 38 & 33 & 0.54 & 0.352 & 40 & 39 & 0.51 & $0.013 \mathrm{~ns}\left({ }^{* *}\right)$ \\
\hline $15 \times 10$ & 31 & 50 & 0.38 & $4.499^{*}$ & 36 & 74 & 0.33 & $13.402^{* * *}(\mathrm{~ns})$ \\
\hline Subtotal & 156 & $191 \dagger$ & 0.45 & 3.536 & 147 & $241 \ddagger$ & 0.38 & $23.001^{* * *}(\mathrm{~ns})$ \\
\hline
\end{tabular}

$\dagger G$ for heterogeneity $=3.584$, d.f. $=3$, ns.

$\ddagger G$ for heterogeneity $=7.158$, d.f. $=3$, ns. 
Table 6 Crosses between MS plants, collected from two wild populations, and hermaphrodites that are heterozygous or homozygously restored at the $m s 1$ locus

\begin{tabular}{|c|c|c|c|c|c|}
\hline \multicolumn{6}{|l|}{ Male parent } \\
\hline \multirow{2}{*}{\multicolumn{3}{|c|}{$\begin{array}{l}\text { Heterozygous } R r \\
\text { MS:H ratio } 1: 1\end{array}$}} & \multirow{2}{*}{\multicolumn{3}{|c|}{$\begin{array}{l}\text { Homozygous } R R \\
\text { MS:H ratio } 0: 1\end{array}$}} \\
\hline & & & & & \\
\hline \multirow[b]{2}{*}{ Cross } & \multicolumn{2}{|c|}{ Offspring } & \multirow[b]{2}{*}{ Cross } & \multicolumn{2}{|c|}{ Offspring } \\
\hline & MS & $\mathrm{H}$ & & MS & $\mathrm{H}$ \\
\hline \multicolumn{6}{|c|}{ Population Strandvlakte (ST) } \\
\hline ST- $11 \times 40-20$ & 0 & $29 * * * \ddagger$ & ST- $11 \times 36-15$ & 0 & 24 \\
\hline ST- $14 \times 36-13$ & 14 & 13 & ST- $14 \times 40-28$ & 0 & 24 \\
\hline ST- $23 \times 36-8$ & 0 & $27^{* * *}$ & ST- $23 \times 36-10$ & 0 & 25 \\
\hline ST- $69 \times 36-13$ & 12 & 14 & ST- $69 \times 36-10$ & 0 & 31 \\
\hline \multicolumn{6}{|c|}{ Population Waddendijk (WA) } \\
\hline WA- $1 \times 36-15$ & 15 & 15 & WA- $1 \times 36-15$ & 1 & 38 \\
\hline WA- $5 \times 36-2$ & 31 & $8^{* * *}$ & WA- $5 \times 36-10,15 \dagger$ & 38 & $0^{* * *}$ \\
\hline WA- $16 \times 36-2,13 \dagger$ & 17 & 22 & WA-16 $\times 40-11$ & 0 & 38 \\
\hline WA- $29 \times 36-13$ & 15 & 7 & WA- $29 \times 36-15$ & 34 & $0^{* * *}$ \\
\hline WA- $31 \times 36-13$ & 22 & 20 & & & \\
\hline
\end{tabular}

$†$ The second plant was used for additional pollination because of a shortage of pollen from the first plant.

$\ddagger$ This figure includes four male steriles that are morphologically and genetically distinct from the MS-type studied in the present paper (unpublished result).

yielded only $\mathrm{H}$ plants irrespective of the male genotype (Table 6). The MS plants from the other population also had a divided reaction: for three of them (WA-1, WA-16, and WA-31) the results are congruent with the involvement of the $m s I$ locus (assuming that the one MS plant in the WA- $1 \times 36-15$ cross is due to an error), but the results for the other two WA plants were clearly different. The results for the crosses WA- $5 \times 36-2$ and the WA- $29 \times 36-13$ are homogeneous $(G=0.949$, d.f. $=1$, ns $)$, and fit a $3: 1$ ratio $(G=0.005$, d.f. $=1$, ns $)$. The results for the deviating plants in each population are strikingly similar, while the pattern differs between populations. Both the $R r$ and the $R R$ males that were used for the Strandvlakte plants, ST-11 and ST-23, apparently carry alleles that restore completely the male sterility of these plants, but not of the msl male sterility. This may be due to an independent locus for male sterility and/or to a cytoplasmic difference. The results with WA-5 and WA-29 leave the possibility open that the $m s l$ locus plays a role, but other loci and/ or cytoplasmic differences may also be involved here. In conclusion, the $m s l$ locus is only one of the factors determining male sterility in $P$. coronopus. In a forthcoming paper it will be shown that inheritance of male sterility in this species is nuclear-cytoplasmic, as is the case in many other gynodioecious species.

\section{Discussion}

The study was deliberately started with a single female parent, as the aim was to find a line with variation at only a single nuclear male sterility locus. Although simple ratios were obtained in the first generation from crosses between male sterile (MS) and hermaphrodites $(\mathrm{H})$ and also selfings of the hermaphrodites, formal proof that a single locus was involved turned out to be complicated. A shortage of MS plants in the second generation of selfed $\mathrm{H}$ plants (Table 2) was in part environmentally induced and caused by drought in the Petri dishes just after germination. In this respect the observed heterogeneity within family 43 after droughting (Tables 2 and 3 ), and the apparent absence of the effect in family 36 (Table 3 ), could be due to chance effects since the drought in the Petri dishes was uncontrolled. Results from the experiment in which the intensity of pollen competition was varied indicated that the remaining shortage was due to selection against $r$ pollen (i.e. pollen carrying the recessive allele which fails to restore male fertility). However, in accepting the case for gametophytic selection the following needs to be borne in mind. Firstly, although the offspring ratio of MS to $\mathrm{H}$ plants from crosses between MS and heterozygous $\mathrm{H}$ parents did fit the 1:1 
ratio under conditions of low but not high levels of pollen, the heterogeneity test resulted in a probability just at the border of significance $(P=0.052)$. The observed MS fraction in the low competition group was 0.45 . Probably, competition was not completely absent in the low treatment as up to 40 grains were applied per style, while $P$. coronopus has only five ovules per flower. Consequently some gametophytic selection may have occurred. Secondly, the effect of gametophytic selection was not observed in all crosses, in particular not in the first generation (Table 1) and in the second generation of selfings of family 43 (Tables 2 and 3). Moreover, in one of the four test crosses for pollen competition, the effect was also absent (Table 5). There seems to be no recognizable pattern in this variation among crosses. In this respect it was of interest that there was no relationship between the occurrence of gametophytic selection and inbreeding level (the maximum inbreeding level in this study was attained in the second generation of selfing, i.e. the progenies in Table 2). Since the selection effect was discovered during the study, and the intensity of pollination was not accurately controlled during the crosses presented in Tables 1-4, chance variation could be partly responsible for the pattern of variation of the gametophytic selection effect. Alternatively, unknown differences in genetic background, for example with respect to the degree of protogyny (Bos et al., 1985) or the stickiness of pollen (Tonsor, 1985) could play a role.

Support for an effect of genetic background on gametophytic selection comes from the greater heterogeneity among than within families in the second generation of selfing (Table 3). Applying the correction for gametophytic selection to the family totals of all three families in Table 2 and comparing the two progeny series shows that gametophytic selection is sufficient to explain the results for both progeny series of family 36, which confirms that selective seedling mortality in the first series is not a necessary factor. In contrast, correcting the second series of family 43 for gametophytic selection yields a strongly significant result. Here selective seedling mortality is sufficient to explain the results. Finally, in family 40 both factors are of influence on segregation of MS.

Gametophytic selection has been found to occur in a number of species but its genetic basis has not often been established (Snow \& Mazer, 1988 and references cited therein). The phenomenon has been documented in several dioecious species (Silene pratensis and $S$. dioica Corens, 1921; Van Nigtevecht, 1966; Rumex hastulatus Rychlewski \& Zarzycki, 1975; Conn \& Blum, 1981), where female biased sex ratios are thought to arise through a higher competitive ability of pollen carrying $\mathrm{X}$ chromosomes. The only example in relation to male sterility that I am aware of, and a good parallel to the present study, is in Triticum where selection was found to act against pollen carrying a recessive male sterility gene (Hossain \& Driscoll, 1981).

One could ask whether, instead of invoking gametophytic selection a more complicated genetic model could explain the results. The model should be extended in the direction of major nuclear genes, since only one cytoplasmic source was used (except possibly in Table 6 of course). The shortage of MS plants in the selfings would often fit a $3: 13$ ratio instead of $1: 3$. This could be explained by a two-locus model with a dominant male sterility gene, say $D$, at the second locus so that $r r D D$ and $r r D d$ are MS. Selfing of the double heterozygote would yield a 3:13 ratio. This model, the combination of a recessive and a dominant male sterility gene, has been used by other authors (Lewis \& Crowe, 1956; Van Damme, 1983), but it is unlikely to apply to the present study for two reasons.

1 The $\mathrm{H}$ plants in the selfing of the double heterozygote would in part be segregating when selfed, and in part non-segregating, as in the one-locus case, but their frequencies would be different: instead of a $2: 1$ ratio, it would be $6: 7$. The latter ratio does not fit the observed ratio of segregating and non-segregating $\mathrm{H}$ in Table 2 $(24: 14, G=4.43$, d.f. $=1, P<0.035)$.

2 Furthermore, two of the five non-segregating $\mathrm{H}$ genotypes should segregate MS when crossed with MS plants in fractions varying among genotypes from 0.25 to 1.0. This phenomenon has not been observed in eight such crosses (Table 4 and 5 ). The probability of this result under the two-locus model can be calculated to be 0.011 .

Other nuclear models can be ruled out in a similar way. All results are qualitatively explained by the onelocus model. The only problem is the shortage of MS in many of the progenies, and this can be adequately explained by genotype-specific reactions to drought just after germination and to competition between pollen. To what extent these selective differences are peculiar to the $m s l$ locus or of the genetic background of the source plant remains to be seen. The crosses of $R R$ and $R r \mathrm{H}$ plants to MS plants collected in the wild showed clear and simple ratios (Table 6). Furthermore, both observed selection effects are typically dependent on the environment, and whether they occur in nature depends on germination conditions and on factors determining pollen loads in the field. The selection against $r$ pollen at high pollen loads would predict male sterile frequencies in the field to be density dependent. It is noteworthy that the direction of both effects is contrary to any negative pleiotropic effect on fitness of 
the restorer allele and also contrary to the maintenance of male sterility. These possible implications are interesting in relation to the evolutionary dynamics of gynodioecy.

\section{Acknowledgements}

I would like to thank $\mathrm{H}$. Schat for providing the seeds of the original mother plant of this study. Part of this work was carried out at the Genetic Institute of the University of Groningen and subsidized by BIONZWO. H. P. Koelewijn, J. Ouborg and J. W. Woldendorp read an earlier draft of the manuscript.

\section{References}

Bos, M., STeEn, R. AND harmens, H. 1985. Protogyny in Plantago lanceolata populations: an adaptation to pollination by wind? In: Jacquard, P., Heim, G. and Antonovics, J. (eds) Genetic Differentiation and Dispersal in Plants, SpringerVerlag, Berlin, pp. 327-338.

CHARLESWORTH, D. 1981. A further study of the problem of the maintenance of females in gynodioecious species. Heredity, 46, 27-39.

CONN, J. S. AND BLUM, U. 1981. Sex ratio of Rumex hastatulus: the effect of environmental factors and certation. Evolution, 35, 1108-1116.

CONNOR, H. E. AND CHARLESWORTH, D. 1989. Genetics of male sterility in gynodioecious Cortaderia (Gramineae). Heredity, 63, 373-382.

CORRENS, C. 1921. Zweite Fortsetzung der Versuche zur experimentellen Verschieben des Geschlechtsverhaltnisses. Sitzungsber. Preuss. Akad. Wiss. Phys.-Math Klasse, 25, 330-354.

Dowling, R. E. 1933. The reproduction of Plantago coronopus: An example of morphological and biological seed dimorphism. Ann. Bot., 47, 861-872.

FRANK, S. A. 1989. The evolutionary dynamics of cytoplasmic male sterility. Am. Natur., 133, 345-376.

GOUYON, P. H. AND COUVET, D. 1985. Selfish cytoplasm and adaptation: variations in the reproductive system of thyme. In: Haeck, J. and Woldendorp, J. W. (eds) Structure and Functioning of Plant Populations 2, North Holland
Publ. Co., Amsterdam, pp. 299-320.

GOUYON, P. H. AND COUVET, D. 1987. A conflict beween two sexes, females and hermaphrodites. In: Stearns, S.C. (ed.) The Evolution of Sex and its Consequences, BirkhauserVerlag, Basel, pp. 245-261.

GOUYON, P. H., VICHOT, F. AND VAN DAMME, J. M. M. 1990. Nuclearcytoplasmic male sterility: single point equilibria versus limit cycles. Am. Natur. in press.

HOSSAIN, M. A. AND DRISCOLL, C. J. 1981. Transfer of cornerstone male-sterility mutant to tetraploid wheat and hexaploid and octoploid triticales. Can. J. Genet. Cytol., 23, 493-496.

KaUL, M. L. H. 1988. Male Sterility in Higher Plants. SpringerVerlag, Berlin.

KESSELI, R. AND JAIN, S. K. 1984. An ecological genetic study of gynodioecy in Limnanthes douglasii (Limnanthaceae). Am. J. Bot., 71, 775-786.

KHEYR-POUR, A. 1981. Wide nucleo-cytoplasmic polymorphism for male sterility in Origanum vulgare L. J. Hered., 72, 45-52.

LEWIS, D. AND CROWE, L. K. 1956. The genetics and evolution of gynodioecy. Evolution, 10, 115-125.

RYCHLEWSKI, J. AND ZARZYCKI, K. 1975. Sex ratio in seeds of Rumex acetosa L. as a result of sparse or abundant pollination. Acta Biol. Crac. Series Bot., 18, 101-114.

SNOW, A. A. AND MAZER, S. J. 1988. Gametophytic selection in Raphanus raphanistrum: a test for heritable variation in pollen competitive ability. Evolution, 42, 1065-1075.

SOKAL, R. R. AND ROHLF, F. J. 1981. Biometry. Freeman \& Co, San Francisco.

Sun, M. 1987. Genetics of gynodioecy in Hawaiian Bidens (Asteraceae). Heredity, 59, 327-336.

TONSOR, S. J. 1985. Intrapopulational variation in pollenmediated gene flow in Plantago lanceolata L. Evolution, 39, 775-782.

VAN DAMME, J. M. M. 1983. Gynodioecy in Plantago lanceolata L. II. Inheritance of three male sterility types. Heredity, 50, 253-273.

VAN DAMME, J. M. M. AND VAN DELDEN, w. 1982. Gynodioecy in Plantago lanceolata L. I. Polymorphism for plasmon type. Heredity, 49, 303-318.

VAN NIGTEVECHT, G. 1966. Genetic studies in dioecious Melandrium. I. Sex-linked and sex-influenced inheritance in Melandrium album and Melandrium dioicum. Genetica, 37, 281-306. 